\title{
(6) OPEN ACCESS \\ Leadership and the medical registrar: how can organisations support these unsung heroes?
}

\author{
Tim Blake, ${ }^{1,2}$ Andrew Whallett ${ }^{1}$
}

${ }^{1}$ Rheumatology Department, The Dudley Group NHS Foundation Trust, Russells Hall Hospital, Dudley, UK ${ }^{2}$ Warwick Medical School, University of Warwick, Coventry, UK

\section{Correspondence to} Dr Tim Blake, Rheumatology Department, The Dudley Group NHS Foundation Trust, Dudley DY1 2HQ, UK;

timblakewarwick@gmail.com

Received 1 June 2016 Revised 2 August 2016 Accepted 13 September 2016

Published Online First

5 October 2016

\section{CrossMark}

To cite: Blake $T$

Whallett A. Postgrad Med J 2016;92:735-740.

\section{ABSTRACT}

Medical registrars have been described as the 'workhorses' of National Health Service hospitals, being at the interface of acute and chronic health services. They are expected to demonstrate effective leadership skills. There are concerns from the Royal College of Physicians that medical registrars are being overwhelmed and unsupported by organisations, and are struggling in their ability to provide safe, high-quality patient care. Junior colleagues are also being deterred by general medical specialties by the prospect of becoming the 'Med Reg'. There is a growing need to support medical registrars in several key aspects of training, not least medical leadership. Thus far, there has been a distinct disparity in the provision of medical leadership training for junior doctors in the UK that has adversely affected the standard of care given to patients. Recent landmark reviews and initiatives, principally the Medical Leadership Competency Framework, have raised awareness of leadership competencies for all doctors and the need for their incorporation into undergraduate and postgraduate curricula. It is hoped that interactive strategies to engage medical registrars in leadership training will lead to positive results including improvements in interdisciplinary communication, patient outcomes and fulfilment of curriculum competencies. Organisations have a duty to improve the quality of medical leadership training so that doctors feel equipped to influence change throughout their careers and be tomorrow's leaders. This review outlines the deficiencies in training, the importance of developing leadership skills in medical registrars and educational strategies that could be implemented by organisations in a cost-effective manner.

\section{THE MEDICAL REGISTRAR AND THE SCOPE OF THE PROBLEM}

Historically, the medical registrar, 'The Med Reg', has been a fundamental and crucial member of any hospital, with many seeing their role in a positive way and as an apt opportunity to develop their decision-making and leadership skills. The role of The Med Reg on the acute take has appropriately been to manage acutely and chronically ill patients in an unselected manner, particularly outside normal working hours. However, today's medical registrars appear to have become disillusioned: it is often stated that the medical registrar's role is one of the most unrewarding and challenging jobs to undertake, and a rite of passage that middle-grade doctors must endure before they take up more attractive consultant posts. ${ }^{1}$ Particular difficulties are experienced pertaining to the intensity and demands of the role and the poor work-life balance. ${ }^{2-4}$ These challenges have also influenced junior doctors' career choices in recent years, leading to difficulties in recruiting for certain medical specialties. ${ }^{5-9}$ The current issues with medical registrar working, deficiencies in leadership training and possible solutions are discussed herein.

There are likely to be several key reasons why this role has become perceived as being arduous and underfulfilling. Over the last 20 years, there have been dramatic changes to the working patterns of all grades of hospital doctors, not least because of restriction on working hours and conditions from the Working Time Regulations (1998) and Modernising Medical Careers (2005). ${ }^{10}{ }^{11}$ Such well-meaning initiatives to reduce doctors' working hours have not led to proportionate improvements in job satisfaction and work-life balance. Although most would agree that overtired and overstretched doctors are not best placed to be assessing acutely unwell patients, changes in shift patterns have led to fragmentation of the junior workforce and reduction in exposure to traditional clinical medicine. A recent UK Medical Careers Research Group survey found only a modest improvement in perception of time for leisure five years after graduation, which was lower among medical specialties. ${ }^{12}$ The registrar's leadership role has also been affected by the fragmentation of these working arrangements. With the introduction of Hospital at Night systems, there are now often coordinators who field urgent and non-urgent calls, making it harder for conscientious registrars to take charge of the wards and supervise their junior colleagues out of normal working hours. ${ }^{13}$ Moreover, as of an ever-increasing number of elderly and complex medical admissions, registrars now often find themselves engaged in routine tasks such as clerking.

With this is mind, the Medical Workforce Unit at the Royal College of Physicians explored the issues and devised pragmatic roles of the medical registrar so that these could hopefully be standardised across hospitals. Their report, 'Empowering the unsung heroes of patient care', drew on the synthesis of opinions of medical registrars from a series of focus groups, with the aim of creating solutions and recommendations. $^{3}$ Key observations from the report were that medical registrars unanimously felt that leading the take team was one of the most important and enjoyable roles they fulfil when on-call, and they cherished the ability to interact and liaise with a variety of different team members, often with different agendas. Nevertheless, many registrars felt that leadership was not given adequate recognition as a training requirement.

\section{THE NEED}

Educationalists Swanwick and McKimm inform us that clinical leadership involves 'setting a vision for 
people, and inspiring and setting organisational values and strategic direction'. ${ }^{14}$ Leadership skills have traditionally been neglected from postgraduate training programmes across all specialties, although they are starting to become more widely recognised. The specialty training board for General Internal Medicine has made several amendments to the curriculum, to reflect this under-representation. ${ }^{15}$ To this end, trainees in all core medical specialties are now expected to achieve the desired level of competence in several aspects of leadership with the aid of workplace-based assessments and quality improvement projects.

This has recently been echoed in two landmark reports looking at the future of junior doctors' working, in which it is suggested that trainee doctors be given more opportunities in education, leadership and management (similar to specialty fellowships). ${ }^{16}{ }^{17}$ These 'out-of-programme' activities will hopefully allow trainees to gain wider experiences and to become more rounded professionals. The sixth edition of A Reference Guide for Postgraduate Specialty Training in the UK (also known as the Gold Guide) sets out the arrangements agreed by the four UK health departments for specialty training programmes and supports such out-of-programme experiences. ${ }^{18}$ The General Medical Council has also released guidance on leadership and management for junior doctors. ${ }^{19}$

\section{Solutions and strategies}

There have been several pivotal initiatives put forward to address these deficiencies. 'Engaging doctors in leadership: a review of the literature' provided one with a helpful summary of the available literature on the impact of engagement and experience of involving doctors in leadership. ${ }^{20}$ It found evidence to suggest that doctors have the most influence when it comes to implementing changes within an organisation, although there was a paucity of data to suggest a positive impact of medical engagement on organisational performance. Key to this report was the finding from international experience (covering Australia, New Zealand, Denmark, Sweden, Finland, Norway, the Netherlands and Germany) that there is little postgraduate training for leadership roles in the UK compared with these other developed countries. Denmark stood out as the country where leadership roles are strongly supported, specifically by representation of physicians on all hospital boards and clinical departments. Doctors there are also encouraged to pursue mandatory postgraduate training that is based on demonstrating core competencies in seven roles (derived from CanMEDS approach developed in Canada).

In addition, the Enhancing Engagement in Medical Leadership project was a UK-wide initiative undertaken jointly by the Academy of Medical Royal Colleges and the National Health Service (NHS) Institute for Innovation and Improvement. ${ }^{21}$ It sought to nurture a culture of engagement, whereby doctors are able to take more of an active role in the planning, delivery and transformation of NHS services. A fundamental part of this project was the creation of the Medical Leadership Competency Framework (MLCF), designed to ensure that all medical students and doctors acquire competence in several aspects of leadership and management, and recognise this as being integral to their role.

There is now much more appreciation of the need for good quality leadership training in the junior doctor years but how does this apply to everyday working and practice? Stanton and Warren provide us with an overview of resources that are currently available for trainees interested in developing their leadership skills, complimentary to their training, although none are matched to the grade of doctor. ${ }^{22}$ Methodologies range from self-directed learning to one-to-one action learning, coaching and mentoring. Although middle-grade doctors of all specialties are likely to exercise similar professional needs in the work environment, there can be little doubt that medical registrars often feel that they are taking on added responsibilities compared with more junior staff and rely on elusive leadership skills to perform effectively.

Ensuring the necessary leadership behaviours, strategies and qualities are developed seems fundamental, but what do we really know about the evidence base for the effectiveness of existing leadership development programmes? The Faculty of Medical Leadership and Management, The King's Fund and the Center for Creative Leadership collectively initiated a review of the evidence by a team including clinicians, managers, psychologists, practitioners and project managers. ${ }^{23}$ This included a review of different types of interventions to promote leaders' effectiveness, including 360-degree feedback, assessment centres, developmental assignments, job rotation, action learning, mentoring and coaching. They concluded that the evidence for these interventions was variable and suggested that future approaches to developing leaders, leadership and leadership strategy should be based on robust theory with strong empirical support and evidence of what works in healthcare. This should ideally be done in an economical way with return on NHS investment.

\section{EDUCATIONAL INITIATIVES FOR SERVICE PROVIDERS}

Board leadership is most effective when boards not only listen to patient voices as the most important sources of feedback on organisational performance, but also to staff voices to ascertain how they can support and enable staff. In order to drive the necessary leadership behaviours of being a medical registrar and promote delivery of high-quality patient care, education and service providers may wish to consider the development of a programme of learning in which trainees can reflect on certain areas of the leadership framework and enrich their behaviours and skills to apply to their individual clinical environments.

Two important aspects of medical leadership and domains of the MLCF-'demonstrating personal qualities' and 'working with others'-are discussed herein. The London Leadership Academy supplies a range of user-friendly resources to facilitate the development of such a mini toolkit. ${ }^{24}$

\section{DEMONSTRATING PERSONAL QUALITIES}

Barrick and Mount introduced five key dimensions that have been shown to mould success in the workplace: ${ }^{25}$

- emotional stability

- extroversion

openness

- agreeableness

- conscientiousness.

\section{Myers-Briggs type inventory}

As well as these domains, effective leaders should be able to do five tasks: inspire people, focus their efforts, enable them to do their job, reinforce their efforts (managing both good and bad performance) and help them to learn. Nevertheless, there is likely to be more to effective leadership than recognising and exemplifying particular positive attributes; importantly colleagues can be drawn together by differences as long as they are working to a common goal. This is depicted by the Myers-Briggs type inventory (MBTI), shown in table 1 , which is becoming more used in a range of working environments to 
Table 1 The dimensions of Myers-Briggs type indicator

\begin{tabular}{|c|c|c|}
\hline \multirow{2}{*}{$\begin{array}{l}\text { Where a person focuses his or } \\
\text { her attention }\end{array}$} & Extraversion (E) & (I) Introversion \\
\hline & Tend to focus on the outer world of people and things & Tend to focus on the inner world of ideas and impressions \\
\hline \multirow{2}{*}{$\begin{array}{l}\text { The way a person gathers } \\
\text { information }\end{array}$} & Sensing (S) & (N) Intuition \\
\hline & $\begin{array}{l}\text { Tend to focus on the present and on concrete information } \\
\text { gained from their senses }\end{array}$ & $\begin{array}{l}\text { Tend to focus on the future, with a view towards patterns and } \\
\text { possibilities }\end{array}$ \\
\hline \multirow{2}{*}{$\begin{array}{l}\text { The way a person makes } \\
\text { decisions }\end{array}$} & Thinking $(\mathrm{T})$ & (F) Feeling \\
\hline & $\begin{array}{l}\text { Tend to base their decisions primarily on logic and on } \\
\text { objective analysis of cause and effect }\end{array}$ & $\begin{array}{l}\text { Tend to base their decisions primarily on values and on subjective } \\
\text { evaluation of person-centred concerns }\end{array}$ \\
\hline \multirow{2}{*}{$\begin{array}{l}\text { How a person deals with the } \\
\text { outer world }\end{array}$} & Judging (J) & (P) Perceiving \\
\hline & $\begin{array}{l}\text { Tend to like a planned and organised approach to life and } \\
\text { prefer to have things settled }\end{array}$ & $\begin{array}{l}\text { Tend to like a flexible and spontaneous approach to life and prefer to } \\
\text { keep their options open }\end{array}$ \\
\hline
\end{tabular}

acknowledge differences and provide focus for improvement, although at some financial cost. Medical registrars engaging in this exercise are likely to find value in understanding their personality type, how and why they make decisions and the repercussions of their actions on others. For example, a person who sees themself as a feeling type may experience a higher degree of emotional involvement in a patient's care and may benefit from discussing this with colleagues. It is important to note, however, that the MBTI depends on honest self-reporting, and the studies underpinning it are methodologically fairly weak. ${ }^{26}$

\section{Emotional intelligence}

Clearly, personality and self-awareness are paramount to the development of oneself as a leader; however, it is likely that certain traits regarded as positive for clinical performance do not automatically translate into markers of good leadership. Moreover, it may be that a person is self-aware although he/she does not consider the wider implications of their actions on others. For that reason, trainees could be introduced to the notion of emotional intelligence (EI or EQ). EI was christened by Goleman, when he found that while the qualities traditionally associated with leadership such as intelligence, toughness, determination and vision are required for success, they are insufficient. ${ }^{27} \mathrm{He}$ observed that effective leaders are also distinguished by a high degree of EI. Mintz and Stoller extended the available literature by compiling a systematic review and found there were wide-ranging strategies to develop physician leadership and EI, including models that use both self-created and externally validated measurement methods. ${ }^{28}$ With evermore focus on patient safety and quality of healthcare, EI seems to have evolved from a desirable to a necessary behaviour. Medical registrars should not see this initiative as a threat or challenge to their authority, but as a valuable opportunity to reflect on their strengths and weaknesses. Such an approach is also likely to serve as an important defence against medical error. Recognising that emotions affect everyone's performance and behaviour and knowing when to ask for help is paramount. $^{29}$

It is often difficult to ascertain which components of EI are the most critical at specific times during the career of a physician and how these should be integrated into the ever-increasing burden of skills and knowledge that competent physicians require. It would be important to look at the longterm outcomes of EI training on patient, physician and hospital system outcomes.

\section{The Johari window}

The Johari window was created by two American psychologists to help people better understand their relationship with themselves as well as others, ${ }^{30}$ and has been validated for use in the healthcare setting. ${ }^{31}{ }^{32}$ It is illustrated in table 2. During the exercise, subjects are given a list of adjectives from which they pick those that best match their own personality. The subject's peers are then given the same list, and each picks an equal number of adjectives that describe the subject, inserting these adjectives into the grid. The window represents an arrangement of learning and development needs with the underlying assumption that if deficiencies are out in the open, then they can be more effectively addressed. The aim is to try to move learning needs into the 'open' quadrant where what needs to be learnt is known to both learner and teacher. This approach could easily be included in mentee-mentor meetings. An extension to this exercise can involve therapeutic confrontation, which has been shown to broaden a student's understanding in a wide variety of patient care situations. $^{33}$

\section{Concentric circles}

The concentric circles exercise allows subjects to take these concepts further and identify areas that they can and cannot control or influence, and subsequently develop an action plan that can address issues within their circle of influence. It is a useful

Table 2 Creating a Johari window

\begin{tabular}{|c|c|}
\hline Open pane & Blind pane \\
\hline $\begin{array}{l}\text { Reflects the 'open book' area of } \\
\text { ourselves: our attitudes, behaviour, } \\
\text { motivation, values, way of life } \\
\text { Record here the knowledge that you } \\
\text { and others have of you } \\
\text { Expand the pane as you learn more }\end{array}$ & $\begin{array}{l}\text { When others provide feedback in a } \\
\text { supportive, responsible way, and you } \\
\text { can take it that way, you are able to } \\
\text { test the reality of who you are and } \\
\text { grow in self-awareness } \\
\text { Record here feedback that has given } \\
\text { you useful insights }\end{array}$ \\
\hline Hidden pane & Unknown pane \\
\hline $\begin{array}{l}\text { The degree to which we share } \\
\text { ourselves with others (disclosure) is } \\
\text { the degree to which we can be known } \\
\text { Record here what you keep to yourself } \\
\text { Ask yourself whether sharing that } \\
\text { knowledge will benefit your } \\
\text { relationships }\end{array}$ & $\begin{array}{l}\text { Be open to experiences that seem to } \\
\text { reveal something from your } \\
\text { subconscious like feelings, reading, } \\
\text { listening and dreaming } \\
\text { Record here chance experiences }\end{array}$ \\
\hline
\end{tabular}




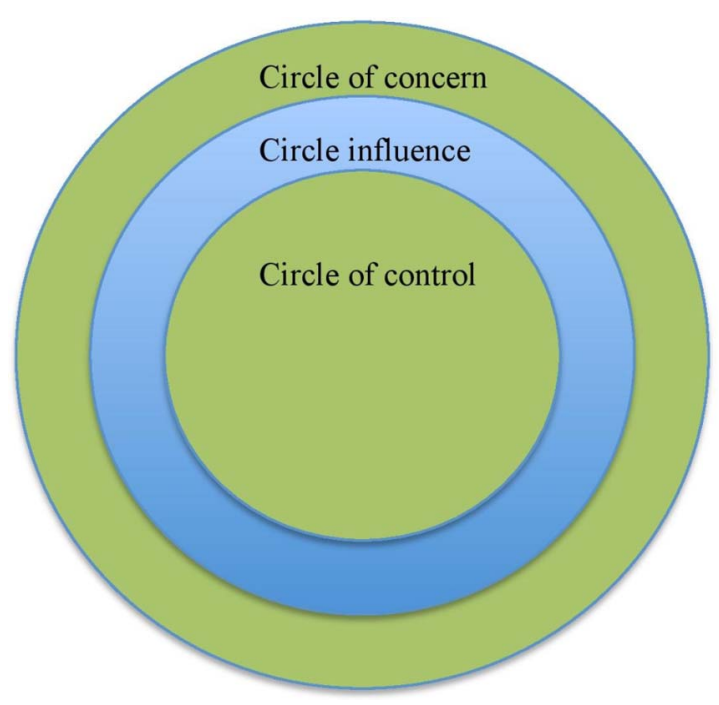

Figure 1 Concentric circles way of thinking.

reminder that even with the best leadership profile in the world there are often times when things are out of our control. Figure 1 and table 3 illustrate this concept and give an example of an action plan. Such an approach can allow doctors to reflect on important aspects of service delivery and what changes may be possible.

Thinking in terms of concentric circles:

- The circle of concern: comprises all matters that you care about.

- The circle of influence: includes all things that you have direct influence over and is able to increase or decrease in size according to what you can influence.

- The circle of control: incorporates all the things that you have direct and full control of, within your circle of influence.

\section{WORKING WITH OTHERS}

Spurgeon and Klaber state that the development of a culture of learning and feedback within a ward setting not only has an impact on personal qualities, but is also crucial to successful teamwork. ${ }^{34}$ There are clearly several reasons why working within the ward environment can flatten one's confidence in leadership, not least because of historical hierarchies in clinical medicine that effectively dictate who should talk to who.

Effective leadership requires individuals to work collaboratively in teams to deliver and improve services, which is largely dependent on building and maintaining relationships and developing networks. Video-based role-play can allow subjects to

Table 3 Developing an action plan based on concentric circles

\begin{tabular}{|c|c|}
\hline What can you influence? & $\begin{array}{l}\text { Actions you can take in your circle of } \\
\text { influence }\end{array}$ \\
\hline $\begin{array}{l}\text { List items from your 'circle of } \\
\text { influence' that you have marked with } \\
\text { a star }\end{array}$ & $\begin{array}{l}\text { Write one or more actions that you can } \\
\text { take that will impact on the issue and } \\
\text { describe what success will look like for } \\
\text { you }\end{array}$ \\
\hline What can you 'potentially' influence? & Actions you can take over time \\
\hline $\begin{array}{l}\text { List items from your 'circle of } \\
\text { influence' that you have marked with } \\
\text { a star }\end{array}$ & $\begin{array}{l}\text { Write one or more actions that you } \\
\text { could possibly take to influence these } \\
\text { issues }\end{array}$ \\
\hline
\end{tabular}

reflect on the use of listening skills and consider the five levels of listening in improving consultation skills.

\section{SPIN approach}

Working with others is just as much about networking and influencing others as it is about getting along with colleagues. SPIN assists the subject in planning questions for important tasks and is outlined below:

- Situation questions

- Problem questions

- Implication

- Need pay-off questions

With such a customised and reciprocal approach, it is expected that one would be more successful in achieving their desired goal. If anything, it enables a person to be structured in their thinking and questioning so that a workable solution can be found more easily. Such a framework may provide medical registrars with the confidence and presentation skills to raise important issues at senior management level.

\section{Difficult conversation planner}

The 'difficult conversation planner' can act as a useful tool when one is faced with an unwanted conversation with a team member, patient or member of a patient's family, knowing that the topic, situation or the person's state of mind could make the discussion difficult. This relatively simple task can allow participants to consider their reactions and subsequent responses to counter arguments, and provide them with a toolkit of strategies for dealing with awkward responses.

All of these exercises are mapped to the MLCF and can be easily incorporated into a training event with little hassle and administration time. They can allow a large proportion of trainees to undertake leadership training in a non-threatening environment, and if anything, provide food for thought on an under-represented topic. A proposed training event is depicted below.

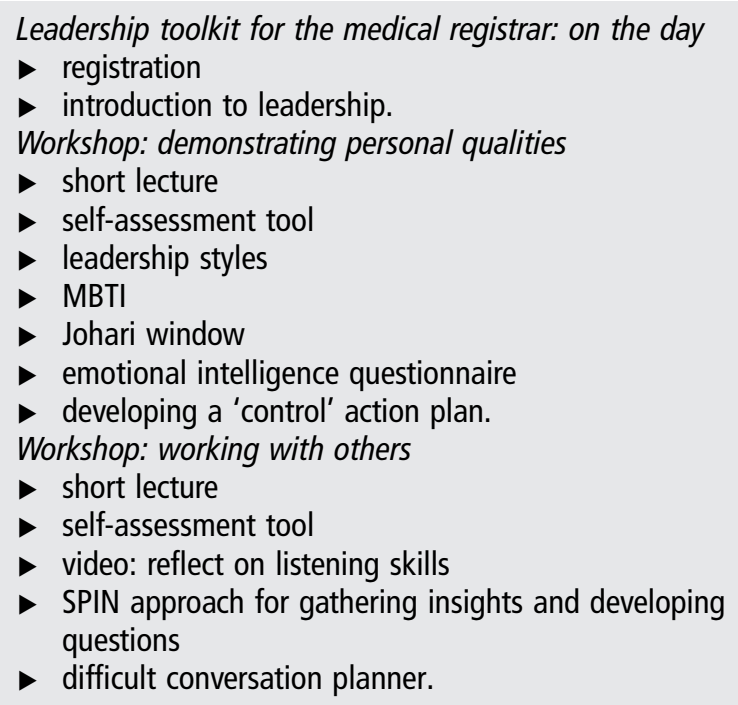

\section{SUMMARY}

Whatever the perceived future benefits of medical leadership, it would seem essential for medical registrars on the shop floor to demonstrate an understanding of health care service provision, resource allocation and the drivers for change within their 
- There is widespread support among policymakers that securing greater medical engagement at all levels is critical to improving health outcomes.

- Medical leadership should be given more prominence in postgraduate medical training at both national and local level to allow medical registrars to feel more supported.

- The key to securing a future culture of medical engagement is empowering junior doctors to take the lead on a wide range of service improvement initiatives.

- The NHS requires leaders to engage with staff and those outside their organisations in different ways.

- Medical registrars should be encouraged to partake in formal leadership training using interactive and reflective techniques to promote understanding of how and why they make decisions and the repercussions of their actions on others.

\section{Current research questions}

- How can we further develop evidence-based approaches to leadership training for medical registrars?

- Can specific leadership training for medical registrars lead to important outcomes within health care services, including patient satisfaction, patient mortality, organisational financial performance, staff well-being, engagement, turnover, absenteeism and overall quality of care?

- What are the most cost-effective means to promote leadership training in junior doctors given the huge financial investment?

\section{Key references}

- NHS Institute for Innovation and Improvement and Academy of Medical Royal Colleges. Medical Leadership Competency Framework: Enhancing Engagement in Medical Leadership. 2010. http://www.leadershipacademy.nhs.uk/wpcontent/uploads/2012/11/NHSLeadership-LeadershipFramework-Medical-Leadership-Competency-Framework3rd-ed.pdf

- Chaudhuri E, Mason N, Logan S. The medical registrar: empowering the unsung heroes of patient care. London: Royal College of Physicians, 2013. http://www.rcplondon.ac. uk/sites/default/files/future-medical-registrar_1.pdf

- General Medical Council. Leadership and management for all doctors. 2012. http://www.gmc-uk.org/Leadership_and_ management_for_all_doctors_English_1015.pdf_ 48903400.pdf

- Spurgeon P, Klaber B. Working with others on the wards. Medical Leadership: a practical guide for tutors and trainees. BPP Learning media, 2011:39-43.

- Clark J, Morgan D. Improving the effectiveness of health services: the importance of generating greater medical engagement in leadership. 2007. http://www.institute.nhs. uk/images/documents/BuildingCapability/Medical_ Leadership/scopingstudyreport110507.pdf

\section{Self assessment questions}

Please answer true (T) or false (F) to the below statements.

1. Medical leadership in the health and care services is about delivering high-quality services to patients by
A. Demonstrating personal qualities
B. Working with others
C. Managing services
D. Improving services
E. Setting direction

2. The MLCF is a key tool that can be used to
A. Help with the design of training curricula and development programmes
B. Assess one's leadership knowledge
C. Help with personal development planning and career progression
D. Highlight individual strengths and development areas through self-assessment and structured feedback from colleagues
E. Compare junior doctors' performance

3. Goleman describes five core characteristics of emotional intelligence:
A. Self-awareness
B. Self-regulation
C. Motivation
D. Empathy
E. Reflection

4. With reference to leadership and management for junior doctors, the General Medical Council states that

A. The work of multidisciplinary teams is primarily focused on the needs of doctors

B. The formal leader of the multidisciplinary team is accountable for the performance of the team

C. The formal leader of the multidisciplinary team is accountable for identifying problems, solving them and taking the appropriate action

D. One must be willing to work with other people and teams to maintain and improve performance, and change systems where this is necessary for the benefit of patients

E. One should respect the leadership and management roles of other team members, including non-medical colleagues

5. A Reference Guide for Postgraduate Specialty Training in the UK (Gold Guide 2016)

A. Provides guidance to postgraduate deans on the arrangements for specialty training in the UK

B. Is applicable to all trainees in General Medical Council-approved programmes, whether in substantive or locum appointment for training posts

C. States that time out of programme can only be agreed if it has the formal approval of the postgraduate dean

D. Includes a section titled Leadership and Management for trainees

E. Applies to all registrars in training

organisation. Clark and Morgan impart that the successful implementation of current and future medical reforms in the NHS 'is very dependent on the support and active engagement of all doctors, not only in their practitioner activities but also in their managerial and leadership roles'. Nowadays, there is a 
recognition that fully trained doctors must be involved in all levels of the country's medical structure in order for optimal changes to take place. ${ }^{35}$

The proposed educational strategies in this review go some way to nurturing medical registrars with respect to medical leadership and engagement, and have the added bonus of fulfilling certain necessary competencies of the generic curriculum. They could be adapted by organisations and incorporated into a programme of learning, provided this could be done with appropriate guidance and support and subsequent evaluation. Organisations have a duty to develop and implement leadership strategies that will promote their values and meet the healthcare needs of the populations they serve.

Such an educational programme has some limitations. One could argue that leadership is an innate personal quality that does not lend itself well to being 'taught'. Some would also contend that leadership training should only be offered to those who are specifically interested. ${ }^{28}$ That said, what the landmark MLCF highlights is that traits and competencies are different: a trait being an inborn quality, and a competency an intended outcome of learning, therefore the recipe for success is not so much related to the components of the framework but the complex interplay and assimilation of domains. The MLCF has been invaluable in raising awareness of leadership within individuals and organisations, and its proper application is likely to lead to a major change in working culture and practice.

Twitter Follow Tim Blake at @blake_tim

Competing interests None declared.

Provenance and peer review Not commissioned; externally peer reviewed.

Open Access This is an Open Access article distributed in accordance with the Creative Commons Attribution Non Commercial (CC BY-NC 4.0) license, which permits others to distribute, remix, adapt, build upon this work non-commercially, and license their derivative works on different terms, provided the original work is properly cited and the use is non-commercial. See: http://creativecommons.org/ licenses/by-nc/4.0/

\section{REFERENCES}

1 Blakey J, LeJeune I, Levy M, et al. General medicine's recruitment crisis: what happened to all the heroes? BMJ Careers, 4 Apr 2013. http://careers.bmj.com/ careers/advice/General_medicine $\%$ E2\%80\%99s_recruitment_crisis $\% 3$ A_what happened_to_all_the_heroes $\% 3 F$

2 Bell D, Patrick A, Hollick R. The medical registrar role-restoring its status and job satisfaction. 2015. http://www.rcpe.ac.uk/sites/default/files/medical-registrarstatement-sep14-v2.pdf

3 Chaudhuri E, Mason N, Logan S. The medical registrar: Empowering the unsung heroes of patient care. London: Royal College of Physicians. 2013. http://www. rcplondon.ac.uk/sites/default/files/future-medical-registrar_1.pdf

4 Acute care toolkit 8. The medical registrar on call: maximising clinical experience, training and patient care. London: Royal College of Physicians, 2013.

5 Chaudhuri E, Mason N, Newbery N, et al. Career choices of junior doctors: is the physician an endangered species? Clin Med 2013;13:330-5.

6 Tasker F, Newbery N, Burr B, et al. Survey of core medical trainees in the United Kingdom 2013-inconsistencies in training experience and competing with service demands. Clin Med 2014;14:149-56.

7 Goldacre MJ, Goldacre R, Lambert TW. Doctors who considered but did not pursue specific clinical specialties as careers: questionnaire surveys. J $R$ Soc Med 2012;105:166-76.

8 Goldacre MJ, Laxton L, Lambert TW. Medical graduates' early career choices of specialty and their eventual specialty destinations: UK prospective cohort studies. BMJ 2010;341:c3199.

9 Oriel. Specialty Recruitment: Round 1-Acceptances and fill rates (England). 2016. http://www.oriel.nhs.uk/Web/News/Edit/MTA20A\%3d\%3d

10 Grant P, Goddard A. The role of the medical registrar. Clin Med 2012;12:12-13.

11 Whallett $\mathrm{A}$, Coleman JJ. In the balance: evolving trends in the satisfaction of junior doctors inside and outside work. Postgrad Med J 2016;92:185-6.
12 Surman G, Lambert TW, Goldacre M. Doctors' enjoyment of their work and satisfaction with time available for leisure: UK time trend questionnaire-based study. Postgrad Med J 2016;92:194-200.

13 Blakey JD, Guy D, Simpson C, et al. Multimodal observational assessment of quality and productivity benefits from the implementation of wireless technology for out of hours working. BMJ Open 2012;2:e000701.

14 Swanwick T, McKimm J. ABC of clinical leadership. BMJ Books: Wiley-Blackwell, 2011.

15 Joint Royal Colleges of Physicians Training Board. Specialty curriculum for General Internal Medicine. 2012. http://www.jrcptb.org.uk/sites/default/files/2009GIM (amendment 2012).pdf

16 Shape of training: securing the future of excellent patient care. 2013. http://www. gmc-uk.org/Shape_of_training_FINAL_Report.pdf_53977887.pdf

17 Future Hospital Commission: caring for medical patients. A report to the Royal College of Physicians. 2013. http://www.rcplondon.ac.uk/projects/outputs/ future-hospital-commission

18 COPMeD. The Gold Guide Sixth Edition: A Reference Guide for Postgraduate Specialty Training in the UK. Version GG6 ed 2016. http://www.copmed.org.uk/ publications/the-gold-guide

19 General Medical Council. Leadership and management for all doctors. 2012. http:// www.gmc-uk.org/Leadership_and_management_for_all_doctors_English_1015. pdf_48903400.pdf

20 Ham C, Dickinson H. Engaging Doctors in Leadership: What we can learn from international experience and research evidence. 2008. http://www.aomrc.org.uk/doc view/198-engaging-doctors-what-can-we-learn-from-international-experience-andresearch-evidence

21 NHS Institute for Innovation and Improvement and Academy of Medical Royal Colleges. Medical Leadership Competency Framework: Enhancing Engagement in Medical Leadership. 2010. http://www.leadershipacademy.nhs.uk/wp-content/ uploads/2012/11/NHSLeadership-Leadership-Framework-Medical-LeadershipCompetency-Framework-3rd-ed.pdf

22 Stanton E, Warren O. Leadership opportunities for trainees. 2010. http://careers.bmj. com/careers/advice/Leadership_opportunities_for_trainees

23 West M, Armit KA, Loewenthal L, et al. Leadership and Leadership Development in Health Care: The Evidence Base. 2015. http://www.kingsfund.org.uk/sites/files/kf/ field/field_publication_file/leadership-leadershipdevelopment-health-care-feb-2015. pdf

24 London Leadership Academy. Leadership Toolkit. 2015. http://www. londonleadingforhealth.nhs.uk/leadershiptoolkit

25 Barrick M, Mount M. The Big Five personality dimensions and job performance: a meta-analysis. Personnel Psychol 1991;44:1.

26 Gardner W, Martinko M. Using the Myers-Briggs type Indicator to study managers: a literature review and research agenda. J Manag 1996;22:45-83.

27 Goleman D. Working with emotional intelligence. London: Bloomsbury, 1998

28 Mintz LJ, Stoller JK. A systematic review of physician leadership and emotional intelligence. J Grad Med Educ 2014;6:21-31.

29 Stanton E, Noble D. Emotional intelligence. 2010. http://careers.bmj.com/careers/ advice/view-article.html?id=20001646

30 Luft J, Ingham H. The Johari window, a graphic model of interpersonal awareness Los Angeles: University of California, 1955.

31 Verklan MT. Johari window - a model for communicating to each other. J Perinat Neonatal Nurs 2007;21:173-4.

32 Halpern H. Supervision and the Johari window: a framework for asking questions. Educ Prim Care 2009;20:10-4.

33 Sutherland JA. The Johari Window: a strategy for teaching therapeutic confrontation. Nurse Educ 1995;20:22-4.

34 Spurgeon P, Klaber B. Working with others on the wards. Medical leadership: a practical guide for tutors and trainees. BPP Learning media, 2011:39-43.

35 Clark J, Morgan D. Improving the effectiveness of health services: the importance of generating greater medical engagement in leadership. 2007. http://www. institute.nhs.uk/images/documents/BuildingCapability/Medical_Leadership/ scopingstudyreport110507.pdf

\section{Answers}

1. $A(T) ; B(T) ; C(T) ; D(T) ; E(T)$

2. $A(T) ; B(F) ; C(T) ; D(T) ; E(F)$

3. $A(T) ; B(T) ; C(T) ; D(T) ; E(F)$

4. $A(F) ; B(T) ; C(F) ; D(T) ; E(T)$

5. $A(T) ; B(T) ; C(T) ; D(F) ; E(F)$ 